\title{
BOS response to article on 'Hold that smile' campaign
}

\author{
S. J. Littlewood ${ }^{1}$ on behalf of the British Orthodontic Society
}

\section{Key points}

Highlights that the British Orthodontic Society's 'Hold that smile' campaign set out to educate

patients about relapse and the importance

of wearing and maintaining retainers after

orthodontic treatment to reduce the chances of

relapse in the long-term.
Discusses the scientific background that supports this campaign
Stresses the importance of collaboration between a patient's orthodontist and general dental practitioner.

The British Orthodontic Society launched a campaign called 'Hold that smile' to highlight to patients the importance of wearing retainers as a means of reducing relapse following orthodontic treatment. This opinion piece, on behalf of the British Orthodontic Society, is written in response to an article entitled 'British Orthodontic Society's initiative on orthodontic retention, A GDP's perspective' (BDJ 2018; 224: 481-486). In this short opinion article, we take the opportunity to clarify the aims of the campaign, which set out to educate patients about orthodontic relapse and to highlight the importance of wearing, and taking responsibility for, retainers long-term.

\section{Introduction}

We write in response to the analysis ${ }^{1}$ of the British Orthodontic Society (BOS) 'Hold that smile' retention campaign by Dr Paul McCrory and welcome the opportunity to provide clarity on some of the pertinent issues he raises. That an awareness campaign designed to improve patients' understanding of their role and responsibilities warranted such a scientific and detailed appraisal is gratifying. We wholeheartedly agree with some of the points raised, namely:

\section{Aligners versus fixed appliances}

The article correctly mentions that the risks of relapse are just as likely with the use of clear aligner treatment, so the challenges of retaining the result are just as relevant whichever type of appliance is used.

\section{Further research}

Longitudinal research is needed into the long-term effects of orthodontic treatment. We don't disagree that 'a definitive evidence base on orthodontic retention could take

${ }^{1}$ Consultant Orthodontist, Orthodontic Department, St Luke's Hospital, Little Horton Lane, Bradford, BD5 ONA, UK Correspondence to: Simon Littlewood

Email: simonjlittlewood@aol.com

Refereed Paper. Accepted 17 April 2018

DOI: 10.1038/sj.bdj.2018.439 in the region of 100 years to develop', but in the meantime, the British Orthodontic Society's view is that we need to base our clinical practice on the best available evidence, which suggests that long-term wear of retainers reduces the risk of relapse.

\section{Valid consent}

This important topic should include informing patients of the commitment required to maintain retainers, which may involve costs in replacing retainers later in life. This is clearly challenging, particularly for patients who may have had treatment for free under the National Health Service, so providing full information to the patient in advance of their treatment is vital.

4. The complexity of orthodontic treatment We agree that the initiative does not reflect the complexities of orthodontic retention, but the purpose of the campaign was to deliver simple key messages to patients.

\section{Life-long records}

We agree this is desirable but currently would be impractical. Perhaps this will change with the advent of secure, centralised, electronic medical records that can be accessed by each individual patient.

The following points raised in the article require further clarification.

\section{The campaign and its reach}

The success of the 'Hold that smile' awareness campaign will be judged by its impact and the number of people reached. Evaluation of both is ongoing. We worked to ensure the messages were patient-friendly and worked closely with the BOS patient panel who generously shared their time and views on the key messages. With their enthusiastic support, we created two videos, ${ }^{2}$ one for patients, the other for the profession and an animation aimed at younger patients. We also published targeted news releases aimed at both the consumer and national press and achieved positive news coverage in several national newspapers, including The Times, The Telegraph and the Daily Mail and all the UK dental media as well as the WFO Gazette. The number of YouTube views identified in the article is misleading. The videos were reposted to new links after subtitles were added and the first wave of views was lost. Without the repostings, the views would now number several thousand. Additionally, Simon Littlewood was interviewed on Irish radio and the American Association of Orthodontists, the largest specialist dental specialty organisation in the world with over 18,000 members, sought permission to share the videos in the US. Evaluations on both reach and impact 
are due to be underway at both the Eastman Dental Institute and King's Dental Institute.

\section{Evolving advice on retention}

Previous generations of orthodontic patients were advised to wear orthodontic retainers for a short period (typically 1-2 years). However, as our understanding of the long-term changes in the position of teeth after orthodontics has improved, the advice about wearing retainers has evolved. The phrase that many orthodontists use is to wear the retainers 'for as long as you want straight teeth. This advice is built on a wealth of evidence from a number of studies over many years. ${ }^{3-10}$ As the video was aimed directly at the public, the intention was not to run through lists of scientific studies in this area, so the classic work that was undertaken in the University of Washington, in Seattle, was quoted in the video. ${ }^{11}$ The research identified that $70 \%$ of patients needed retreatment. The research team looked at the patients who didn't show relapse, but were unable to identify factors that may allow us to predict which patients were stable and which would relapse. ${ }^{11}$ This is a result that has been found in a number of long-term relapse studies: it is not possible at the present time to predict who will relapse and who will remain stable. As a result, we have to presume that everyone has the potential to relapse.

\section{Tooth movement and the ageing process}

In the video, some of the long-term unwanted changes in the occlusion were referred to as part of the normal ageing process. The article observes that the changes in tooth position could be due to other factors like late mandibular growth and physiological mesial drift. Most orthodontists would regard these factors as normal age changes. Interestingly, research following up patients for 40 years who initially presented with good occlusions, with no need for orthodontic treatment, show the same sort of unwanted changes in their occlusion with age. ${ }^{12}$

\section{CQC regulation of retention}

The BOS does not feel that further regulation would be helpful in this area, either for the patient or the profession.

\section{Responsibility for retention}

This is a challenging topic and another area where we are in agreement with Dr McCrory. Current thinking, ${ }^{13}$ summarised by our retention authority and author of this response, Simon Littlewood, is that responsibilities are shared between the orthodontist, the patient and the general dental practitioner. Close cooperation is required. The retention issue is a challenge that affects patients all over the world, ${ }^{14}$ although the problems differ according to the type of remuneration system.

\section{The symbiotic relationship between orthodontist and GDP}

The BOS is very aware of the important role played by GDPs in monitoring retainers. We believe it is incumbent on us to provide ongoing support to our practitioner colleagues and their input and feedback is invaluable. As itemised in the table in Dr McCrory's article, the BDA's Vice-President commented on the lack of co-ordinated patient information on retention and described the campaign as 'a welcome addition. BOS also had the support of the Faculty of General Dental Practice and we welcomed the responsiveness of both FGDP and BDA. We hope that by highlighting the patient's responsibility for their retainers, we are assisting GDPs who take on a monitoring role once the orthodontic treatment is completed.
In summary, all dental (or indeed medical) interventions have a finite life-span, and this is true for orthodontic treatment. Our 'Hold that smile' campaign is aimed at educating patients about orthodontic relapse and highlighting the importance of wearing, and taking responsibility for, retainers long-term. We are grateful to Dr McCrory for highlighting the campaign, and the Editor of the British Dental Journal for giving us an opportunity to clarify some areas. If we can align the communications of specialists and GDPs, then the interests of our patients will be better served.

1. McCrory P V. British Orthodontic Society's initiative on orthodontic retention, A GDP's perspective. Br Dent J 2018; 224: 481-486.

2. British Orthodontic Society. Orthodontic retention for patients. Available at https://www.bos.org.uk/PublicPatients/Orthodontic-Retention-for-Patients (accessed April 2018).

3. Maltha J C, Von den Hoff J W. Biological basis for orthodontic relapse. In Katsaros \& Eliades (ed) Stability, retention, relapse in orthodontics. pp. 15-28. Surrey, UK: Quintessence, 2017.

4. Nanda R S, Nanda S K. Considerations of dentofacial growth in long-term retention and stability: is active retention needed? Am J Orthod Dentofacial Orthop 1992; 101: 297-302.

5. Behrendts R G. The biological basis for understanding craniofacial growth during adulthood. Prog Clin Biol Res 1985: 187: 307-319.

6. Parker W S. Retention - retainers may be forever. Am J Orthod Dentofacial Orthop 1989; 95: 505-513.

7. Sadowsky C, Schneider B J, BeGole E A, Tahir B S Long-term stability after orthodontic treatment: Nonextraction with prolonged retention. Am J Orthod Dentofac Orthop 1994; 106: 243-249.

8. Boley J C, Mark J A, Sachdeva R C, Buschang P H. Long-term stability of class I premolar extraction treatment. Am J Orthod Dentofac Orthop 2003; 124: 277-287.

9. Kaplan $\mathrm{H}$. The logic of modern retention procedures. Am J Orthod Dentofac Orthop 1988; 93: 325-340.

10. Littlewood S J, Russell J S, Spencer R J. Why do orthodontic cases relapse? Orthodont Update 2: 43-49.

11. Little R M, Wallen T R, Reidel R A. Stability and relapse of mandibular anterior alignment - first premolar extraction cases treated by traditional edgewise orthodontics. Am J Orthod 1981; 80: 349-365.

12. Tsiopas N, Nilner R, Bondemark L, Bjerklin K. A 40 years follow-up of dental arch dimensions and incisor irregularity in adult. Eur J Orthod 2013; 35: 230-235.

13. Littlewood S J. Responsibilities and retention. APOS Trends Orthod 2017: 7: 211-214.

14. Lai C S, Grossen M G, Renkema A-M, Bronkhorst B, Fudilej PS, Katsaros C. Orthodontic retention procedures in Switzerland. A survey. Swiss Dent J 2014; 124: 655-661. 